\title{
The neutrophil-activating protein of Helicobacter pylori promotes Th1 immune responses
}

\author{
Amedeo Amedei, ${ }^{1}$ Andrea Cappon, 2,3 Gaia Codolo, 2,3 Anna Cabrelle, ,3,4 \\ Alessandra Polenghi, ${ }^{3,5}$ Marisa Benagiano, ${ }^{1}$ Elisabetta Tasca, ${ }^{3}$ Annalisa Azzurri, ${ }^{1}$ \\ Mario Milco D'Elios, ${ }^{1,6}$ Gianfranco Del Prete, ${ }^{1,6}$ and Marina de Bernard ${ }^{3,5}$
}

\begin{abstract}
1Department of Internal Medicine, University of Florence, Florence, Italy. ${ }^{2}$ Department of Biomedical Sciences, University of Padua, Padua, Italy. ${ }^{3}$ Venetian Institute of Molecular Medicine, Padua, Italy. ${ }^{4}$ Department of Clinical and Experimental Medicine and ${ }^{5}$ Department of Biology, University of Padua, Padua, Italy. ${ }^{6}$ Department of Biomedicine, Azienda Ospedaliera Universitaria Careggi, Florence, Italy.
\end{abstract}

\begin{abstract}
The Helicobacter pylori neutrophil-activating protein (HP-NAP) is a virulence factor of $H$. pylori that stimulates in neutrophils high production of oxygen radicals and adhesion to endothelial cells. We report here that HP-NAP is a TLR2 agonist able to induce the expression of IL-12 and IL-23 by neutrophils and monocytes. Addition in culture of HP-NAP, as an immune modulator, to antigen-induced $\mathrm{T}$ cell lines resulted in a remarkable increase in the number of IFN- $\gamma$-producing T cells and decrease of IL-4-secreting cells, thus shifting the cytokine profile of antigen-activated human $T$ cells from Th2 to a Th1 cytotoxic phenotype. We also found that in vivo HP-NAP elicited an antigen-specific Th1-polarized $\mathrm{T}$ cell response in the gastric mucosa of $\mathrm{H}$. pylori-infected patients. These data indicate HP-NAP as an important factor of $H$. pylori able to elicit cells of the innate immune system to produce IL-12 and IL-23, and they suggest it as a new tool for promoting Th1 immune responses.
\end{abstract}

\section{Introduction}

Helicobacter pylori, a Gram-negative microaerophilic bacillus that infects more than $50 \%$ of the human population, has been associated with various gastroduodenal diseases (1-4). H. pylori colonization is followed by infiltration of the gastric mucosa by polymorphonuclear leukocytes, macrophages, and lymphocytes (5). H. pylori infection induces an immune response, which is not sufficient to either prevent or counteract bacterial colonization; rather, it actually contributes to chronic gastric inflammation (6).

Two of the major $H$. pylori virulence factors are the vacuolating cytotoxin (VacA) and the H. pylori neutrophil-activating protein (HP-NAP) $(7,8)$. VacA has also been proposed as a modulator of immune cell function because of its capacity to interfere with antigen presentation and to inhibit $\mathrm{T}$ cell activation $(9,10)$. HP-NAP, an oligomeric protein of $150 \mathrm{kDa}$, was initially identified as a promoter of endothelial adhesion of neutrophils and was designated as neutrophil-activating protein because it stimulates high production of oxygen radicals from neutrophils (11). In addition, HP-NAP increases in monocytes the synthesis of tissue factor and the secretion of type 2 plasminogen activator inhibitor $(8,12)$. HP-NAP is chemotactic for neutrophils (8), but it is not yet known whether this cell type participates in creating a particular cytokine environment at the site of infection. The cytokine profile produced during the immune response to $H$. pylori may represent an important factor capable of influencing the outcome of the infection.

In a mouse model of H. pylori infection, administration of purified VacA results in epithelial erosion but not in inflammatory cell

Nonstandard abbreviations used: HEK, human embryonic kidney; HP-NAP Helicobacter pylori neutrophil-activating protein; hTLR, human TLR; MFI, mean fluorescence intensity; PHA, phytohemagglutinin M form; SFC, spot-forming cell; TT, tetanus toxoid; VacA, vacuolating cytotoxin.

Conflict of interest: The authors have declared that no conflict of interest exists. Citation for this article: J. Clin. Invest. 116:1092-1101 (2006). doi:10.1172/JCI27177. infiltration (13). Therefore, other factors are presumably involved in generating and maintaining the gastric inflammatory response, and HP-NAP might represent a good candidate.

We have examined the in vitro effect of HP-NAP on human cells of both the innate and the adaptive immunity. HP-NAP was found to be a TLR2 agonist able to stimulate either neutrophils or monocytes to increase their expression of IL-12, a key cytokine for the differentiation of naive Th cells into the Th1 phenotype (14). HP-NAP also induced monocytes to produce IL-23 and to differentiate toward mature DCs. These results suggested that HP-NAP might have the potential to trigger a Th1 differentiation program in $\mathrm{T}$ cells undergoing specific antigen challenge in vitro. Indeed, addition in culture of HP-NAP to antigen-induced T cell lines resulted in a shift from a predominant Th2 to a Th1 phenotype of specific $\mathrm{T}$ cells. Finally, an in vivo correlate of the Th1-polarizing capacity of HP-NAP was provided by the consistent Th1 polarization of the functional profile of a series of HP-NAP-specific CD4 $\mathrm{T}$ cell clones generated from in vivo-activated $\mathrm{T}$ cells derived from the gastric mucosa of $H$. pylori-infected patients. Our data suggest that HP-NAP is an important protein of H. pylori able to promote the induction of Th1 responses.

\section{Results}

HP-NAP stimulates IL-12 and IL-23 production in neutrophil granulocytes. Total RNA was extracted from neutrophils incubated with HP-NAP, retrotranscribed, and amplified by real-time PCR in the presence of specific primers. The amounts of mRNA for IL-12p35 and for IL-12p40 were remarkably increased (Figure 1, A and B), though with different kinetics and degree: IL-12p40 mRNA increased more than IL-12p35 messenger, in agreement with the well-known lower abundance of p35 transcripts even in activated inflammatory cells (15). While the expression of IL-12p40 peaked at 6 hours, the increased expression of p35 already observed at 6 hours reached its maximum at 12 hours. The kinetics of cytokine 
A
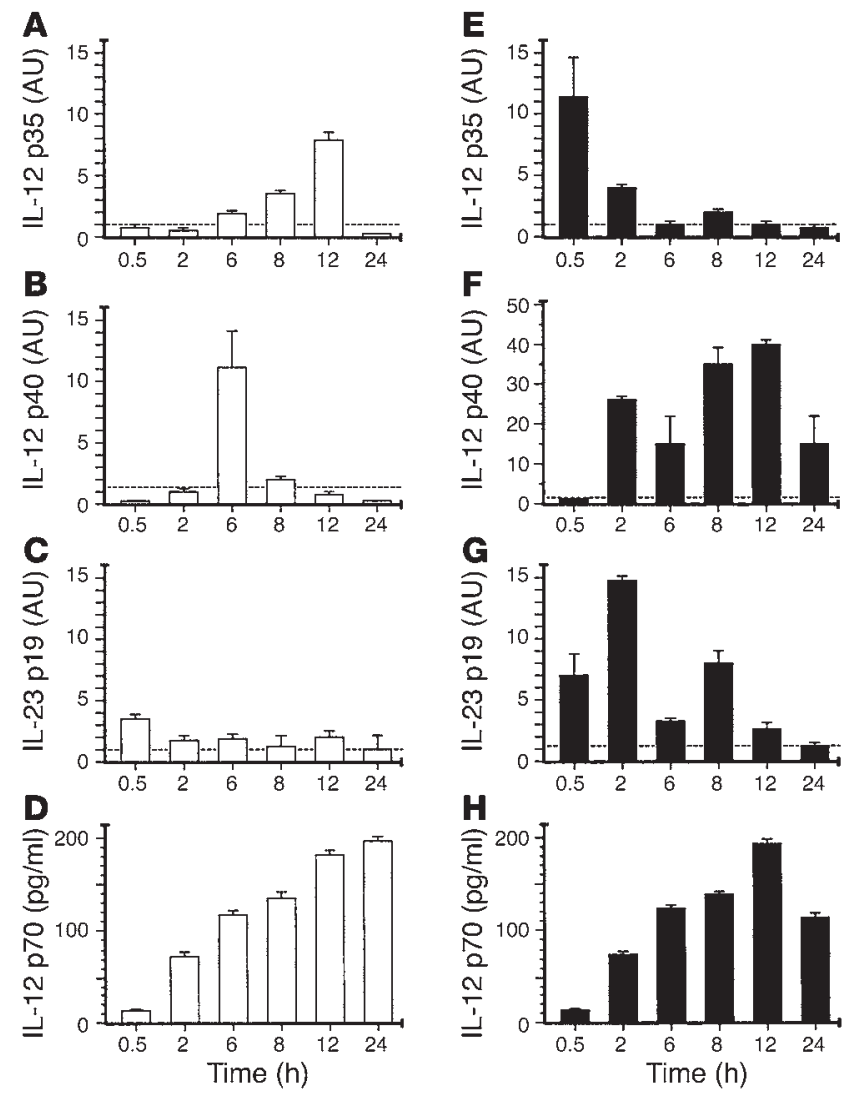

mRNA levels determined by quantitative RT-PCR were consistent with the kinetic of protein accumulation in culture supernatant (Figure 1D). A significant TNF- $\alpha$ mRNA expression was also found after 6 hours of incubation, before decreasing after 8 hours (data not shown).

The $\mathrm{p} 40$ subunit associates not only with IL-12p35, but also with another molecule, p19, to form another heterodimeric cytokine, IL-23 (16). In neutrophils, treatment with HP-NAP resulted in a prompt upregulation of IL-23p19 mRNA that decreased thereafter at minimal levels at 24 hours (Figure 1C).

HP-NAP stimulates IL-12 and IL-23 production in monocytes. To further investigate the effect of HP-NAP on cells of the innate immunity, monocytes isolated from PBMCs of healthy donors were used as targets. HP-NAP was extremely efficient in upregulating the monocyte expression of IL-12p35, IL-12p40, and IL-23p19 mRNAs. In particular, IL-12p35 mRNA showed its peak at 30 minutes (Figure 1E), whereas IL-12p40 mRNA peaked between 8 and 12 hours and was still detectable at 24 hours (Figure 1F). The kinetics of IL-12p40 and IL-12p35 mRNA levels were consistent with the kinetic of IL-12 protein accumulation in the supernatant (Figure 1H). Finally, following HP-NAP stimulation, the monocyte expression of IL-23p19 mRNA (Figure 1G) peaked at 2 hours, followed by a progressive decrease down to baseline levels at 24 hours. These findings indicate that HP-NAP acting on either neutrophils or monocytes contributes to the creation of a cytokine milieu enriched in IL-12 and IL-23, which have the potential to drive the differentiation of antigen-stimulated $\mathrm{T}$ cells toward a polarized Th1 phenotype.

HP-NAP promotes MHC class II upregulation and IL-12 production in monocytes and DCs. While control monocytes incubated with medium progressively died between 28 and 36 hours of culture,

\section{Figure 1}

Kinetics of cytokine mRNA levels and IL-12p70 production in neutrophils and monocytes stimulated with HP-NAP. Cytokine mRNAs in neutrophils $(\mathbf{A}-\mathbf{C})$ and monocytes $(\mathbf{E}-\mathbf{G})$ were determined by quantitative realtime PCR. The experiment shown is 1 representative of 7 experiments conducted with different cell preparations. The dotted lines represent the level of cytokine mRNA produced by mock cells. IL-12p70 protein levels were measured in the culture supernatants of the same neutrophils (D) and monocytes $(\mathbf{H})$ harvested for messenger evaluation. Levels were assessed by a specific ELISA method. IL-12p70 protein levels at time 0 were under the lower limit of sensitivity of the assay $(7.8 \mathrm{pg} / \mathrm{ml})$. The kinetics of production were comparable among different experiments, whereas the amounts varied among different donors.

monocytes incubated with HP-NAP survived longer. In addition, HP-NAP-treated monocytes revealed a progressive shape modification and a tendency to cluster and to detach from the substrate. In order to better characterize these observations, the expression of maturation markers in HP-NAP-stimulated monocytes was evaluated.

Compared with the corresponding baseline values, the expression of HLA-DR increased markedly at day 5 of incubation with HP-NAP (mean fluorescence intensity [MFI] $563 \pm 81$ versus $62.7 \pm 0.7)$ and even more at day $7(1,161 \pm 117$ ) (Figure 2). CD80 expression as well increased significantly at day 5 in comparison with its baseline (MFI 57.2 \pm 15.7 versus $2.5 \pm 1.5$ ) and even more at day 7 (92 \pm 12$)$. Likewise, the expression of CD86, already increased after 5 days (MFI $53.7 \pm 3.7$ ), was remarkably higher at day $7(148 \pm 23)$, as compared with the baseline $(9.1 \pm 1.5)$. In contrast, the expression of CD40, B7-RP1, and B7-H1 was only weakly increased after 5-7 days of stimulation with HP-NAP, whereas the expression of B7-DC and CD83 remained unaffected. No significant change of the expression of the markers was observed in untreated control cells (data not shown). These results suggest that HP-NAP induces the differentiation of monocytes into mature DCs. Furthermore, following 24 hours of stimulation with HP-NAP, DCs produced detectable amounts of IL-12p70 in culture supernatants (mean $\pm \mathrm{SD}, 250 \pm 38 \mathrm{pg} / \mathrm{ml}$ ).

HP-NAP is a TLR 2 agonist. Most TLR ligands are conserved microbial products (pathogen-associated molecular patterns, or PAMPs) that signal the presence of infection, and each TLR is triggered by a distinct set of microbial compounds (17-23). In order to define whether a given TLR was involved in the interaction with HP-NAP, we used human embryonic kidney (HEK) 293 cells transfected with plasmids encoding distinct human TLRs (24, 25). HEK 293 cell lines lack expression of endogenous TLRs, although their TLR signaling machine is fully functional $(17,26)$. NF-KB activation by HP-NAP was determined using an NF- $\mathrm{KB}$-dependent reporter construct. Activation was observed only in cells expressing TLR2, whereas no activation was detectable in HEK 293 cells expressing TLR3, TLR4, TLR5, TLR7, TLR8, or TLR9 (Table 1). Moreover, the activation of NF- $\mathrm{KB}$ by HP-NAP was detectable in TLR2-expressing HEK cells in a range from 0.03 to $1.0 \mu \mathrm{M}$ (Figure 3).

An important point to be addressed was whether other TLR2 agonists, such as PAM2 or PAM3, shared with HP-NAP the ability to induce IL-12 production by monocytes. To this end, graded concentrations of PAM2, PAM3, and HP-NAP were added in cultures of adherent monocytes, and cytokine production was assessed in supernatants after 24 hours. Like HP-NAP, both PAM2 and PAM3 were similarly efficient in inducing TNF- $\alpha$, IL- 6 , and IL-8 produc- 

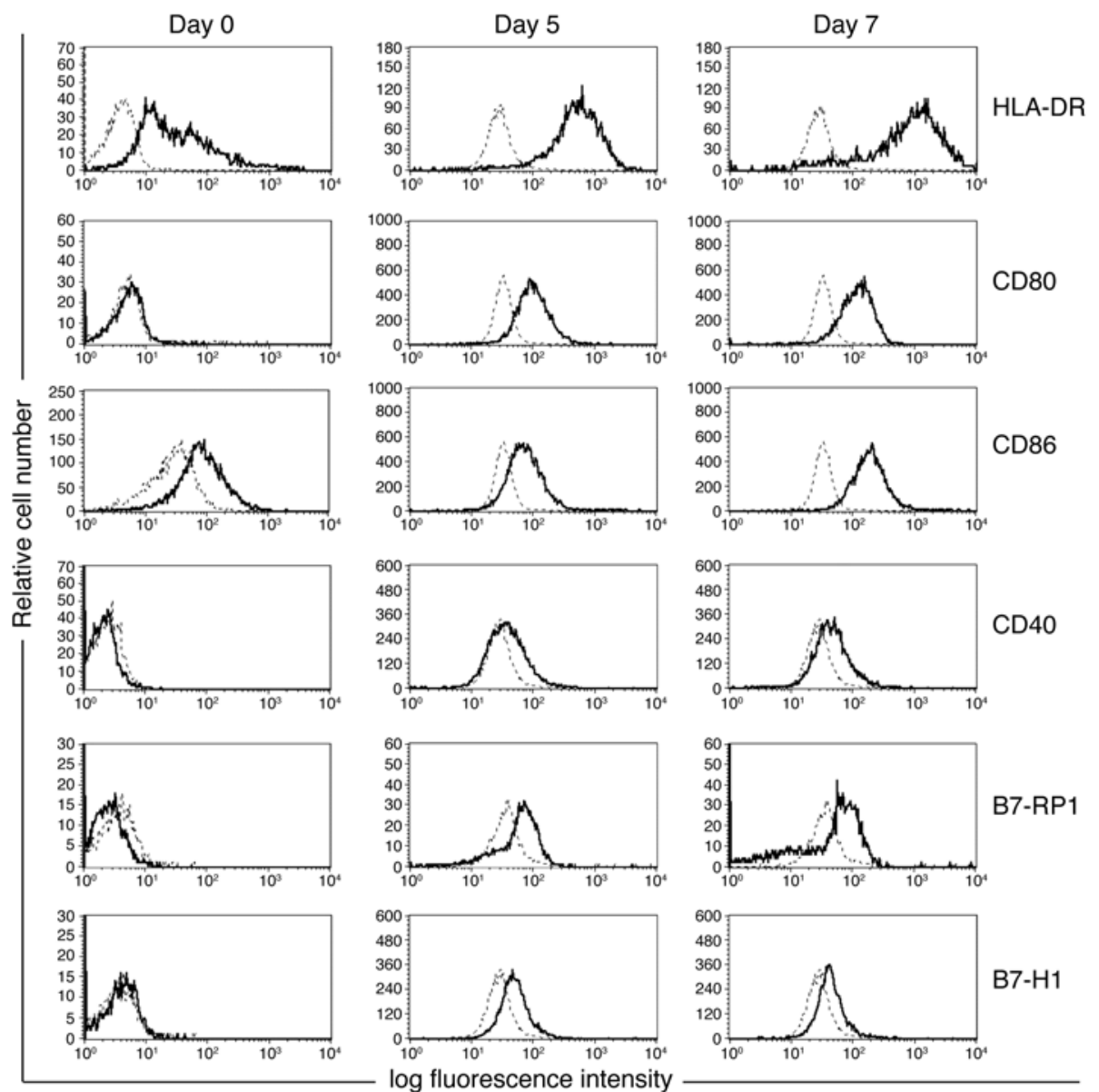

Figure 2

Flow cytometric analysis of HP-NAP-stimulated monocytes and DCs. Solid and dotted lines correspond to HP-NAP-treated monocytes and to isotype controls, respectively. Results of 2 representative of 4 consecutive experiments are reported.

tion by monocytes (Table 2), but only HP-NAP was able to induce IL-12 production in a dose-dependent fashion. In order to rule out that the effects attributed to HP-NAP were due to a contaminating TLR2 ligand, an HP-NAP immune-depleted preparation was tested. As shown in Table 2, immune depletion with an anti-HP-NAP antibody abrogated the induction of cytokine synthesis; likewise, addition in culture of an anti-TLR2 antibody also resulted in abrogation of cytokine production by monocytes (data not shown).

Addition in culture of HP-NAP-null H. pylori mutant results in negligible IL-12 production by adherent monocytes. To better define the role of HP-NAP in the induction of IL-12 secretion by monocytes, an HP-NAP-null $H$. pylori mutant was compared with WT H. pylori for their efficiency in the induction of monocyte cytokine synthesis. Both WT and HP-NAP-null mutant bacteria were able to induce the production of comparable amounts of TNF- $\alpha$, IL- 6 , and IL- 8 by monocytes (Table 3$)$. In contrast, stimulation with the highest dose of HP-NAP-null mutant $H$. pylori $\left(5 \times 10^{5} \mathrm{CFUs} / \mathrm{ml}\right)$ resulted in very poor secretion of IL-12, which was lower than that induced by a 25 times lower concentration of WT H. pylori $\left(0.2 \times 10^{5} \mathrm{CFUs} / \mathrm{ml}\right)$. These data suggest that a number of $H$. pylori components can activate monocytes to cytokine synthesis, but HP-NAP represents the critical molecule for the induction of substantial IL-12 secretion.
Addition in culture of HP-NAP results in preferential development of IFN- $\gamma$-producing $T$ cells and reduction of IL-4-secreting cells. In view of its ability to induce IL-12 and IL-23 secretion by cells of the innate immunity, HP-NAP was tested for its capacity to affect the development of the cytokine profile of tetanus toxoid-specific (TT-specific) T cell responses. PBMCs from 5 TT-reactive donors were stimulated with TT in the presence of medium alone or HP-NAP. T cell blasts of each line were stimulated with the antigen (TT) in the presence of autologous APCs for 24 or 48 hours in ELISPOT microplates coated with anti-IFN- $\gamma$ or anti-IL-4 antibody, respectively. At the end of the culture period, IFN- $\gamma$ or IL-4 spot-forming cells (SFCs) were counted. Conditioning with HP-NAP resulted in a remarkable increase of IFN- $\gamma$-producing $T$ cells and decrease of IL-4-secreting cells $(P=0.029$ and $P=0.05$, respectively) (Figure 4).

$\mathrm{T}$ cell blasts of each TT-induced line were recovered and cloned by limiting dilution according to a high-efficiency protocol $(6,27)$. A total of $168 \mathrm{CD}^{+}$ $\mathrm{T}$ cell clones were obtained from the TT-induced T cell lines in the presence of medium, whereas $152 \mathrm{CD}^{+}$clones were obtained from TT-induced T cell lines generated in the presence of HP-NAP. Of the $168 \mathrm{CD}^{+}$clones generated from the TT-induced lines conditioned with medium, 74 (44\%) were reactive to $\mathrm{TT}$, whereas the other $94 \mathrm{CD} 4+$ clones of this series failed to proliferate in response to the challenge with TT. In the series of 152 clones generated from TT-induced cell lines conditioned with HP-NAP, 72 (47\%) proliferated to the specific antigen stimulation. TT-specific clones of the 2 series were stimulated for 48 hours with TT in the presence of autologous APCs, and IFN- $\gamma$ and IL-4 levels were measured in culture supernatants. In the series of 74 clones from the TT cell lines conditioned with medium, 22 (30\%) expressed a Th1 profile, and 31 (42\%) were Th0 producing both IFN- $\gamma$ and IL-4, whereas 21 (28\%) were Th2 clones (Figure 5, left panel). In contrast, in the series of 72 TT-specific clones from the TT-induced lines conditioned with HP-NAP, 49 (68\%) were Th1 and 21 (29\%) were Th0, whereas only 2 were Th2 (3\%).

Conditioning with PAM2 or PAM3 does not affect the development of IFN- $\gamma$ - or IL-4-producing T cells induced by allergen. In subsequent experiments, PAM2 and PAM3 were compared with HP-NAP for their capacity to affect the development of the cytokine profile of $\mathrm{T}$ cell responses specific to the mite allergen Dermatophagoides pteronyssinus. PBMCs from 5 mite allergen-sensitive donors were stimulated with mite allergen in the presence of medium alone, PAM2 $(50 \mathrm{ng} / \mathrm{ml})$, PAM3 $(50 \mathrm{ng} / \mathrm{ml})$, or HP-NAP $(3.0 \mu \mathrm{M})$. On day 6 , allergen-induced $T$ cell lines were expanded with IL-2. At day 12 , $\mathrm{T}$ cell blasts of each line were stimulated with the specific allergen 
Table 1

HP-NAP-induced activation of NF-KB in HEK 293 cells transfected with plasmid encoding distinct human TLRs

\begin{tabular}{|c|c|c|}
\hline TLR transfected & Ligand & $\begin{array}{c}\text { NF- } \kappa B \text { activation } \\
\text { (mean OD } \pm \text { SD after } \\
24 \text { hours of stimulation) }\end{array}$ \\
\hline \multirow[t]{3}{*}{ hTLR2 } & None & $0.09 \pm 0.01$ \\
\hline & PAM2 & $0.88 \pm 0.09$ \\
\hline & HP-NAP & $0.91 \pm 0.11$ \\
\hline \multirow[t]{3}{*}{ hTLR3 } & None & $0.13 \pm 0.01$ \\
\hline & Poly(I:C) & $0.97 \pm 0.08$ \\
\hline & HP-NAP & $0.13 \pm 0.01$ \\
\hline \multirow[t]{3}{*}{ hTLR4 } & None & $0.07 \pm 0.01$ \\
\hline & LPS & $0.75 \pm 0.08$ \\
\hline & HP-NAP & $0.12 \pm 0.01$ \\
\hline \multirow[t]{3}{*}{ hTLR5 } & None & $0.15 \pm 0.01$ \\
\hline & Flagellin & $1.07 \pm 0.09$ \\
\hline & HP-NAP & $0.14 \pm 0.01$ \\
\hline \multirow[t]{3}{*}{ hTLR7 } & None & $0.08 \pm 0.01$ \\
\hline & $\mathrm{R} 848$ & $0.75 \pm 0.06$ \\
\hline & HP-NAP & $0.09 \pm 0.01$ \\
\hline \multirow[t]{3}{*}{ hTLR8 } & None & $0.12 \pm 0.01$ \\
\hline & R848 & $1.00 \pm 0.13$ \\
\hline & HP-NAP & $0.11 \pm 0.01$ \\
\hline \multirow[t]{3}{*}{ hTLR9 } & None & $0.14 \pm 0.02$ \\
\hline & ODN 1826 & $0.93 \pm 0.11$ \\
\hline & HP-NAP & $0.14 \pm 0.01$ \\
\hline
\end{tabular}

Parallel cultures of HEK 293 cells were cotransfected with expression plasmid encoding 1 single human TLR for each culture, and an NF- $\mathrm{KB}$ dependent luciferase reporter construct. HEK-hTLR-transfected lines were stimulated with HP-NAP $(1.0 \mu \mathrm{M})$, or with appropriate concentrations of the specific TLR-positive control ligands. A recombinant HEK 293 cell line for the reporter gene only was used as a negative control. The NF-кB activation in each line was quantified as OD values after 24 hours of stimulation. Results represent mean OD values \pm SD obtained in a representative of 3 consecutive experiments.

in the presence of autologous APCs for 24 or 48 hours in ELISPOT microplates coated with anti-IFN- $\gamma$ or anti-IL-4 antibody, respectively. At the end of the culture period, IFN- $\gamma$ or IL-4 SFCs were counted. As shown in Table 4, only conditioning with HP-NAP resulted in a remarkable increase of IFN- $\gamma$-producing $\mathrm{T}$ cells and decrease of IL-4-secreting cells $(P<0.0005$ and $P<0.001$, respectively), whereas PAM2 and PAM3 were not effective.

HP-NAP favors the shift of allergen-specific T cell clones from $T h 2$ to Th1 phenotype. In order to assess whether HP-NAP substantially influenced the in vitro development of Th cell responses to allergens usually oriented to the Th2 pattern, allergen-induced $\mathrm{T}$ cell lines were generated from PBMCs of house dust mite allergen-sensitive donors, and medium, HP-NAP, or IL-12 was added at the time of

\section{Figure 3}

Activation of NF-KB in HEK 293 cells transfected with plasmid encoding human TLR2. Parallel culture samples of hTLR2-transfected HEK 293 cells were stimulated with graded concentrations of HP-NAP (from 0.03 to $1.0 \mu \mathrm{M}$ ) (squares), or with graded concentrations of the specific hTLR2-positive control ligand PAM2 (from 0.1 to $10 \mathrm{ng} / \mathrm{ml}$ ) (diamonds). A recombinant HEK 293 cell line for the reporter gene only was used as a negative control (data not shown). The NF-кB activation in each sample was quantified as OD values after 24 hours of stimulation. Results of a representative experiment are reported. allergen exposure in vitro. Stimulation with mite allergen resulted in the expansion of $\mathrm{T}$ cell lines. $\mathrm{T}$ cell blasts of each line were cloned as described previously $(6,27)$. A total of $38 \mathrm{CD}^{+}$clones were obtained from the allergen-induced $\mathrm{T}$ cell lines in the presence of medium, whereas 40 and $55 \mathrm{CD}^{+}$clones were obtained from allergen-induced lines generated in the presence of HP-NAP or IL-12, respectively. Of the $38 \mathrm{CD}^{+}$clones generated from the allergen-induced lines conditioned with medium, 18 (47\%) were reactive to mite allergen. In the series of clones generated from $\mathrm{T}$ cell lines conditioned with HP-NAP, 21 (52.5\%) of the $40 \mathrm{CD}^{+}$ clones proliferated upon allergen challenge, whereas in the series of clones generated from T cell lines conditioned with IL-12, 42\% of the $\mathrm{CD}^{+}$clones were allergen specific.

Allergen-specific $T$ cell clones of the 3 series were stimulated for 48 hours with allergen in the presence of autologous APCs, and IFN- $\gamma$ and IL-4 levels were measured in supernatants. In the series of allergen-specific clones from the $\mathrm{T}$ cell lines conditioned with medium, no clone expressed a Th 1 profile, and $11 \%$ were Th 0 producing both IFN- $\gamma$ and IL-4, whereas $89 \%$ were Th 2 clones (Figure 5, right panel). In contrast, in the series of allergen-specific clones from the allergen-induced lines conditioned with HP-NAP, as many as $38 \%$ were Th 1 , and $33 \%$ were Th0, whereas only $29 \%$ were Th2. As expected, conditioning with IL-12 resulted in the development of a series of allergen-specific clones including 22\% Th1, 52\% Th0, and 26\% Th2. In conclusion, similarly to IL-12, addition in culture of HP-NAP resulted in a shift from preferential type 2 to predominant type $1 \mathrm{~T}$ cell responses, with remarkable expansion of IFN- $\gamma$-producing T cell clones and strong reduction $\left(\chi^{2} 14.347\right.$, $P<0.0001)$ of allergen-specific clones with Th2 profile.

HP-NAP-null H. pylori mutant fails to shift to Th1 the development of allergen-specific T cell clones. In subsequent experiments, WT $H$. pylori and HP-NAP-null H. pylori mutant were compared for their ability to affect the development of the cytokine profile of mite allergen-specific T cell clones. PBMCs were obtained from 3 allergic donors, and for each donor 3 parallel allergen-induced $\mathrm{T}$ cell lines were started: the first was added with medium alone, the second with WT H. pylori $\left(5 \times 10^{5} \mathrm{CFUs} / \mathrm{ml}\right)$, and the third with HP-NAP-null $H$. pylori mutant $\left(5 \times 10^{5} \mathrm{CFUs} / \mathrm{ml}\right)$. After expansion with IL-2 and cloning, the 3 series of clones from each donor were compared for their IFN- $\gamma$ and/or IL-4 production upon allergen stimulation. In the series of 143 allergen-specific clones from lines conditioned with medium, 3 (2\%) were Th1, 54 (38\%) were Th0, and 86 (60\%) were Th2. In contrast, conditioning with WT H. pylori at the time of allergen exposure resulted in a series of 136 allergen-specific clones including 30 (22\%) Th1, 80 (59\%) Th0, and only $26(19 \%)$ Th2 $(P<0.0005)$, whereas conditioning with HP-NAP-null $H$. pylori mutant resulted in 119 allergen-specific clones, of which only 5 (4\%) were Th1, 56 (47\%) Th0, and 58 (49\%) Th2 (Figure 6). These data indicate that WT, but not HP-NAP- 


\section{Table 2}

Cytokine production by adherent monocytes induced by LPS or different agonists of human TLR2

\begin{tabular}{|c|c|c|c|c|}
\hline Stimuli & $\begin{array}{l}\text { IL-12 } \\
(\mathrm{pg} / \mathrm{ml})\end{array}$ & $\begin{array}{l}\text { TNF- } \alpha \\
(\mathrm{pg} / \mathrm{ml})\end{array}$ & $\begin{array}{c}\text { IL-6 } \\
\text { (ng/ml) }\end{array}$ & $\begin{array}{c}\text { IL-8 } \\
\text { (ng/mI) }\end{array}$ \\
\hline Medium & $<8$ & $<75$ & $<0.03$ & $<0.6$ \\
\hline \multicolumn{5}{|l|}{ LPS } \\
\hline$(1 \mu \mathrm{g} / \mathrm{ml})$ & $<8$ & $782 \pm 35$ & $5.15 \pm 0.29$ & $16.55 \pm 0.48$ \\
\hline \multicolumn{5}{|l|}{ PAM2 } \\
\hline (2 ng/ml) & $<8$ & $85 \pm 6$ & $0.78 \pm 0.11$ & $4.00 \pm 0.33$ \\
\hline (10 ng/ml) & $<8$ & $98 \pm 9$ & $1.28 \pm 0.10$ & $8.15 \pm 0.75$ \\
\hline$(50$ ng/ml) & $<8$ & $194 \pm 13$ & $2.23 \pm 0.17$ & $13.35 \pm 1.82$ \\
\hline \multicolumn{5}{|l|}{ PAM3 } \\
\hline (2 ng/ml) & $<8$ & $<75$ & $<0.03$ & $0.63 \pm 0.11$ \\
\hline$(10 \mathrm{ng} / \mathrm{ml})$ & $<8$ & $<75$ & $<0.03$ & $0.88 \pm 0.09$ \\
\hline$(50 \mathrm{ng} / \mathrm{ml})$ & $<8$ & $102 \pm 16$ & $0.15 \pm 0.07$ & $2.13 \pm 0.36$ \\
\hline \multicolumn{5}{|l|}{ HP-NAP } \\
\hline$(0.3 \mu \mathrm{M})$ & $77 \pm 5$ & $144 \pm 17$ & $1.16 \pm 0.09$ & $3.57 \pm 0.41$ \\
\hline$(1 \mu \mathrm{M})$ & $151 \pm 11$ & $292 \pm 20$ & $2.72 \pm 0.18$ & $8.36 \pm 0.67$ \\
\hline$(3 \mu \mathrm{M})$ & $228 \pm 14$ & $505 \pm 38$ & $4.90 \pm 0.37$ & $9.72 \pm 0.85$ \\
\hline $\begin{array}{l}\text { Immune-depleted } \\
\text { HP-NAP preparati }\end{array}$ & $<8$ & $<75$ & $<0.03$ & $<0.6$ \\
\hline
\end{tabular}

Adherent monocytes from peripheral blood of 6 healthy donors were incubated for 24 hours with medium; with graded concentrations of HP-NAP or other TLR-2 agonists, such as PAM2 or PAM3; or with an immune-depleted HP-NAP preparation used at the same dilution that gave a $3-\mu \mathrm{M}$ concentration in the case of nondepleted preparation. Culture supernatants were collected and assayed for their cytokine content by appropriate ELISA assays. Results represent mean values $\pm S D$ obtained in 2 consecutive experiments.

null mutant, H. pylori is able to induce a significant $(P<0.0005)$ Th1 shift of allergen-specific T cells and confirm that HP-NAP is a powerful Th1-polarizing agent in vitro.

Addition in culture of HP-NAP results in preferential development of cytotoxic T cells producing high amounts of TNF- $\alpha$. Since cytolytic activity is a common property of activated Th1 and of most Th0 clones but is usually missing in Th2 clones (28), the cytolytic potential of Th clones was assessed in a lectin-dependent (phytohemagglutinin $\mathrm{M}$ form-dependent) ${ }^{51} \mathrm{Cr}$-release assay with P815 murine mastocytoma cells as targets. At an effector-to-target ratio of 5:1, all the $6 \mathrm{Th} 0$ but none of the $32 \mathrm{Th} 2$ clones generated from allergen-induced $\mathrm{T}$ cell lines conditioned with medium were cytolytic (Figure 7). The mean $( \pm \mathrm{SD})$ percentage specific ${ }^{51} \mathrm{Cr}$ release induced by these $\mathrm{Th} 0$ clones was quite low $(16.5 \% \pm 11 \%)$. In the series of Th clones derived from $\mathrm{T}$ cell lines conditioned with HP-NAP, the 9 Th2 clones were not cytolytic, whereas all the $14 \mathrm{Th} 0$ and the $17 \mathrm{Th} 1$ clones expressed cytolytic activity with a significantly higher specific ${ }^{51} \mathrm{Cr}$ release in comparison with that of clones from lines conditioned with medium $(52 \% \pm 21 \%$, $P<0.0001)$. Significantly higher ${ }^{51} \mathrm{Cr}$ release was still detectable at an effector-to-target ratio of $1: 1(28 \% \pm 15 \%, P<0.0001)$, suggesting that the cytolytic potential of those clones was high. Conditioning with HP-NAP, like IL-12, resulted in the outgrowth of allergen-specific clones, the majority of which showed cytolytic activity.

With regard to the ability of T cell clones to produce TNF- $\alpha$ upon allergen stimulation, in the series of Th clones derived from the lines conditioned with medium, only 3 (9\%) of the $34 \mathrm{Th} 2$ and 5 (83\%) of the $6 \mathrm{Th} 0$ clones produced small amounts of TNF- $\alpha(0.56 \pm 0.39 \mathrm{ng} / \mathrm{ml}$, range $0.12-0.89$, and $0.66 \pm 0.43 \mathrm{ng} / \mathrm{ml}$, range $0.18-1.35$, respectively). In contrast, in the series of Th clones derived from the lines conditioned with HP-NAP, all the 17 Th1 and 13 of the 14 Th0 clones were able to produce high amounts of TNF- $\alpha(3.84 \pm 2.62$ $\mathrm{ng} / \mathrm{ml}$, range $1.40-9.50$, and $3.25 \pm 3.15 \mathrm{ng} / \mathrm{ml}$, range $0.24-9.20$ ), whereas only 3 of the 9 Th 2 clones produced low amounts of that cytokine $(0.12 \pm 0.04 \mathrm{ng} / \mathrm{ml}$, range $0.09-0.17)$. Likewise, in the series of clones derived from the lines conditioned with IL-12, all the 14 Th 1 and the 24 Th0 clones produced high amounts of TNF- $\alpha$ $(5.95 \pm 3.28 \mathrm{ng} / \mathrm{ml}$, range $0.84-10.50$, and $2.90 \pm 2.65 \mathrm{ng} / \mathrm{ml}$, range $0.19-9.50)$, whereas only 9 of the 17 Th2 clones produced low amounts of TNF- $\alpha(0.17 \pm 0.10 \mathrm{ng} / \mathrm{ml}$, range $0.07-0.32)$.

HP-NAP-specific T cells from the H. pylori-induced gastric infiltrates are polarized cytotoxic Th1 cells producing TNF- $\alpha$. In order to assess whether in vitro data reported above had any in vivo correlate, biopsy specimens of antral mucosa from $5 \mathrm{H}$. pylori-infected patients were cultured for 7 days in IL-2-conditioned medium in order to preferentially expand the in vivo-activated $T$ cells present in their antral inflammatory infiltrates. $\mathrm{T}$ cell blasts were recovered and cloned by limiting dilution, as reported previously (6). In a series of 144 $\mathrm{CD}^{+} \mathrm{T}$ cell clones obtained from the 5 gastric biopsies, 27 (19\%) showed significant proliferation to HP-NAP (Table 5).

Upon 48 hours of stimulation with HP-NAP, $100 \%$ of HPNAP-specific gastric clones showed a clear-cut Th1 profile. All the 27 HP-NAP-specific clones produced high amounts of TNF- $\alpha$ $(4.2 \pm 3.3 \mathrm{ng} / \mathrm{ml}$, range $0.75-11.4)$, and all expressed powerful cytolytic activity in the lectin-dependent ${ }^{51} \mathrm{Cr}$-release assay using P815 cells as target cells (Table 5).

In the same series of $144 \mathrm{CD} 4^{+} \mathrm{T}$ cell clones obtained from the gastric biopsies, 30 clones (21\%) were specific for $H$. pylori antigens other than HP-NAP, such as CagA, VacA, and urease. Upon stimulation with the specific $H$. pylori antigen, 25 of 30 clones (83\%) showed a Th1 profile, whereas only 5 were Th0. All clones produced levels of TNF- $\alpha$ comparable to those produced by HP-NAPspecific clones, and 27 of 30 (90\%) expressed cytotoxic activity.

\section{Discussion}

The neutrophil-activating protein of $H$. pylori (HP-NAP), a highly conserved protein among geographically distinct $H$. pylori strains (8), is a member of a broad superfamily of ferritin-like proteins,

\section{Table 3}

Cytokine production by adherent monocytes induced by WT H. pylori or HP-NAP-null $H$. pylori mutant

\begin{tabular}{lcccc}
\hline $\begin{array}{l}\text { H. pylori strain } \\
(\text { CFUs/ml) }\end{array}$ & $\begin{array}{c}\text { IL-12 } \\
(\mathbf{p g} / \mathbf{m l})\end{array}$ & $\begin{array}{c}\text { TNF- } \alpha \\
(\mathbf{p g} / \mathbf{m l})\end{array}$ & $\begin{array}{c}\text { IL-6 } \\
(\mathbf{n g} / \mathbf{m l})\end{array}$ & $\begin{array}{c}\text { IL-8 } \\
(\mathbf{n g} / \mathbf{m l})\end{array}$ \\
$\begin{array}{l}\text { None } \\
\text { WT }\end{array}$ & $<8$ & $<75$ & $<0.03$ & $<0.6$ \\
$\quad\left(0.2 \times 10^{5}\right)$ & $56 \pm 2$ & $112 \pm 10$ & $0.24 \pm 0.11$ & $1.71 \pm 0.08$ \\
$\left(1.0 \times 10^{5}\right)$ & $167 \pm 10$ & $478 \pm 51$ & $0.95 \pm 0.08$ & $4.62 \pm 1.12$ \\
$\left(5.0 \times 10^{5}\right)$ & $313 \pm 24$ & $176 \pm 22$ & $1.45 \pm 0.82$ & $0.82 \pm 0.10$ \\
HP-NAP-null & & & & \\
$\left(0.2 \times 10^{5}\right)$ & $<8$ & $135 \pm 6$ & $0.18 \pm 0.10$ & $1.23 \pm 0.35$ \\
$\left(1.0 \times 10^{5}\right)$ & $17 \pm 2$ & $240 \pm 36$ & $0.89 \pm 0.33$ & $3.48 \pm 0.74$ \\
$\left(5.0 \times 10^{5}\right)$ & $31 \pm 4$ & $137 \pm 26$ & $1.26 \pm 0.37$ & $1.05 \pm 0.47$
\end{tabular}

Adherent monocytes from peripheral blood of 6 healthy donors were incubated for 24 hours with medium or graded concentrations of WT $H$. pylori or HP-NAP-null $H$. pylori mutant. At the end of the culture period, culture supernatants were collected and assayed for their cytokine content by appropriate ELISA assays. Results represent mean values \pm SD obtained in 2 consecutive experiments. 


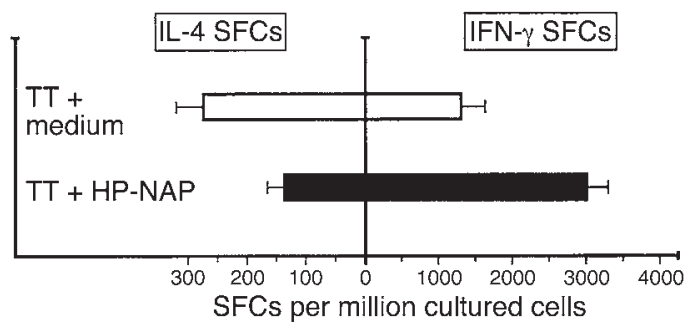

Figure 4

Conditioning with HP-NAP promotes IFN- $\gamma$ production. Addition in culture of HP-NAP together with antigen increases IFN- $\gamma$-producing $T$ cells and reduces IL-4-secreting cells. TT-induced T cell lines were generated from PBMCs of 5 healthy donors in the presence of medium or HP-NAP. T cell blasts of each line were then stimulated with TT in the presence of irradiated autologous APCs, and IFN- $\gamma$ - or IL-4-producing $T$ cells were assessed by specific ELISPOT assays. Results represent mean numbers $( \pm S D)$ of SFCs per million cultured cells counted using an automated ELISPOT reader.

most of which have a DNA-protective function under starved conditions, such as oxidative or nutritional stress, including metal ion starvation (29). Members of this family are homopolymers formed by 12 four-helix bundle subunits that assemble to provide iron ligands (30-32). Earlier studies identified a number of properties of HP-NAP, such as its high immunogenicity, the ability to promote chemotaxis, endothelial adhesion, and high production of oxygen radicals of neutrophils, as well as the synthesis of tissue factor and the secretion of type 2 plasminogen activator inhibitor $(8,12)$. Here we show that incubation of neutrophils with HP-NAP results in prompt and remarkable upregulation of cytokine mRNA expression and protein secretion, including IL-12p35 and IL-12p40, which assemble to form the active IL-12, and IL-23p19, which pairs with the IL-12p40 chain to form IL-23 (16). The very same effects of HP-NAP in terms of cytokine induction and secretion were observed in DCs and peripheral blood monocytes, other cell types belonging to the innate immunity. The kinetics and cytokine levels were rather different between neutrophils and monocytes, the latter cells being in general more efficient in their expression of IL-12p40 and IL-23p19 mRNAs. These findings suggest that HP-NAP, by acting on both neutrophils and monocytes, significantly contributes to inducing a cytokine milieu enriched in IL-12 and IL-23, which have the potential to drive the differentiation of antigenstimulated T cells toward a polarized Th1 phenotype $(14,16)$.

In this study, we also observed that HP-NAP activity on monocytes resulted not only in strong upregulation of Th1-polarizing cytokines, but also in the induction of a progressive and consistent maturation process of monocytes into mature DCs showing high expression of HLA-DR, CD80, and CD86, longer survival, and a tendency to cluster and to detach from the substrate.

DC function is crucial in the regulation of both the early innate immune responses and the subsequent adaptive immunity (23). The process of Th1 development can be influenced by different host and bacterial factors, and the differentiation from immature DCs into mature professional APCs can be induced by whole bacteria or their components, the so-called pathogen-associated molecular patterns (PAMPs), which interact with specific TLRs (23). This process is accompanied by upregulation of MHC class II and costimulatory molecules, together with cytokine produc- tion (33-35). Dose-response experiments showed that HP-NAP is a TLR2 agonist able to activate NF-KB in HEK TLR2-transfected cells, whereas it was inactive on HEK cells transfected with other TLRs. Although it cannot be excluded that a posttranslational modification or a distinct, but closely associated, molecule may take part in TLR2 activation by our HP-NAP preparation, the results obtained in this study suggest that the ability to activate TLR2 mainly depends on the primary sequence of HP-NAP itself.

A previous study on the effects of the interaction between H. pylori and immature DCs showed that the pathogen induced these cells to release in a dose-dependent fashion IL-6, IL-8, IL-10, and IL-12 and represented a maturation stimulus for human monocyte-derived DCs (36). However, the bacterial factor(s) responsible for such effects remained unidentified. Here we demonstrate that HP-NAP can be that bacterial factor, because it is able, alone, to mimic all the reported effects of the entire H. pylori. An in vivo correlate of these in vitro effects is offered by earlier observation of strong upregulation of IL-12p40, IL-12p35, TNF- $\alpha$, and IFN- $\gamma$ mRNAs in biopsies of the antral mucosa of $H$. pyloriinfected patients with severe gastric inflammation and peptic ulcer (6). On the other hand, the possibility exists that factors other than HP-NAP may contribute to the generation of the Th1-type milieu found in the gastric mucosa of $H$. pylori-infected subjects.

In view of the remarkable ability of HP-NAP to induce cells of the innate immunity to upregulate their IL-12 and IL-23 production, we asked whether HP-NAP, besides polarizing to Th1 its specific $\mathrm{T}$ cell response at a gastric level, might have a similar in vitro effect on the development of Th2 responses, such as those elicited by allergens in T cells of allergic subjects. To address this question, allergen-induced $\mathrm{T}$ cell lines were generated from PBMCs of house dust mite allergen-sensitive donors by addition of medium, HP-NAP, or IL-12 together with allergen. As expected, stimulation with allergen plus medium resulted in the expansion of Th2-oriented

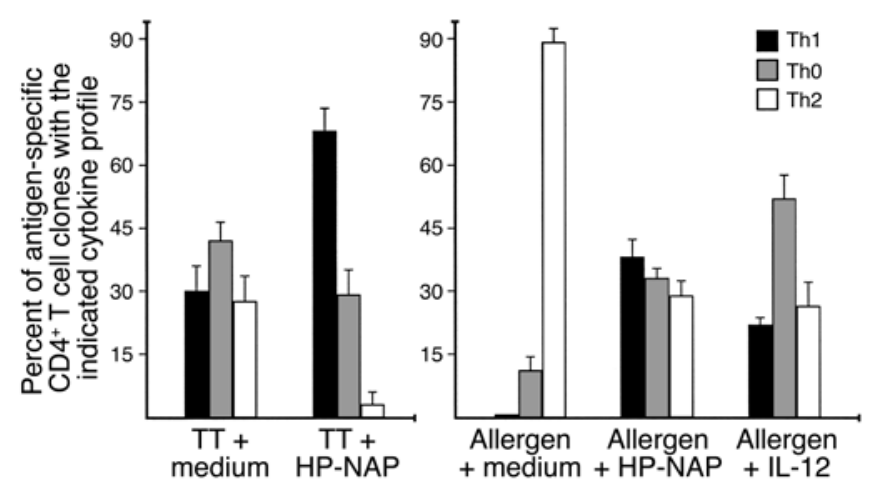

\section{Figure 5}

Conditioning with HP-NAP promotes the Th1 polarization of antigenspecific T cells. TT- or allergen-induced T cell lines (left and right panels, respectively) were generated in the presence of medium alone, HP-NAP, or IL-12. T cell blasts of each line were then cloned, and antigen-specific $T$ cell clones were stimulated for 48 hours with medium or the appropriate antigen in the presence of irradiated autologous APCs. Culture supernatants were then collected and assayed for their IFN- $\gamma$ and IL-4 content. Clones able to produce IFN- $\gamma$, but not IL-4, were categorized as Th1; clones producing IL-4, but not IFN- $\gamma$, were coded as Th2, whereas clones producing both IFN- $\gamma$ and IL-4 were categorized as Th0. Results represent mean percentage proportions ( \pm SD) of clones with the indicated cytokine profile, obtained from series of 3 T cell lines for each condition. 


\section{Table 4}

Allergen-induced IFN- $\gamma$ and IL-4 SFCs in allergen-specific T cell lines conditioned with PAM2, PAM3, or HP-NAP

$\begin{array}{lrc}\text { Conditioning factor } & \text { IFN }-\gamma \text { SFCs } & \text { IL-4 SFCs } \\ \text { Medium } & 855 \pm 168 & 2,180 \pm 316 \\ \text { PAM2 }(50 \mathrm{ng} / \mathrm{ml}) & 907 \pm 112 & 1,976 \pm 213 \\ \text { PAM3 }(50 \mathrm{ng} / \mathrm{ml}) & 798 \pm 131 & 1,992 \pm 268 \\ \text { HP-NAP }(3.0 \mu \mathrm{M}) & 4,634 \pm 248 & 710 \pm 41\end{array}$

PBMCs from 5 mite allergen-sensitive donors were stimulated with mite allergen in the presence of medium alone, PAM2 $(50 \mathrm{ng} / \mathrm{ml})$, PAM3 $(50 \mathrm{ng} / \mathrm{ml})$, or HP-NAP $(3.0 \mu \mathrm{M})$. On day 6 , allergen-induced T cell lines were expanded with IL-2. At day 12, T cell blasts of each line were stimulated with the mite allergen in the presence of irradiated autologous APCs for 24 or 48 hours in ELISPOT microplates coated with anti-IFN- $\gamma$ or anti-IL-4 antibody, respectively. At the end of the culture period, IFN- $\gamma$ or IL-4 SFCs were counted using an automated ELISPOT reader. Results represent mean values \pm SD of SFCs per $10^{6}$ cultured cells over background levels for each condition.

lines and clones showing poor or no cytotoxic activity. In contrast, conditioning with either IL-12 or HP-NAP resulted in a significant shift from polarized Th2 to predominant Th1 allergen-specific $\mathrm{T}$ cell responses, with remarkable expansion of IFN- $\gamma$-producing allergen-specific clones and strong reduction of IL-4-producing Th2 clones. Moreover, the fact that all the Th1 allergen-specific clones from the $\mathrm{T}$ cell lines conditioned with HP-NAP expressed high TNF- $\alpha$ production and powerful cytotoxic activity suggests that the Th1-inducing adjuvant effect of HP-NAP does not merely affect the production of cytokines but also triggers the activation of the cytotoxic program, a typical property of polarized Th1 effector T cells (28). The Th1-polarizing effect of HP-NAP was not limited to allergen-specific $\mathrm{T}$ cell responses, but it was also observed in the $\mathrm{T}$ cell responses to TT detected by ELISPOT experiments, in which conditioning with HP-NAP resulted in a remarkable increase of IFN- $\gamma$-producing T cells and decrease of IL-4-secreting cells. Likewise, conditioning with HP-NAP resulted in Th1 polarization of the cytokine profile of TT-specific T cell clones.

Different types of $\mathrm{T}$ cell responses and cytokine patterns are elicited by infections with pathogens and during the subsequent inflammatory process that are crucial either for infection healing and protection or for pathogen persistence and pathology. On the other hand, in some immunopathological conditions, extreme polarization of Th cell responses is responsible for disease. Atopic allergy, in which IL-4 secretion and polarized Th2 responses are both inappropriate and harmful, is just an example. In atopy and in other conditions of poor Th1 activation, one would need a powerful Th1-polarizing signal, like HP-NAP, to deploy the Th1-polarizing capacity of DCs and to redirect the generation of the $\mathrm{T}$ cell response into a more appropriate and nonpathogenic class. In view of its Th1-promoting activity, HPNAP might represent a new tool for immunotherapeutic protocols, including those with ex vivo-treated DCs devoted to IL-12 induction, e.g., for cancer immunotherapy.

\section{Methods}

Reagents. HP-NAP was cloned, expressed, and purified from Bacillus subtilis to avoid LPS contamination, as described previously (30). Immune-depleted preparation of HP-NAP was obtained with a purified rabbit anti-HP-NAP antibody (37), using a G-Sepharose matrix. Human recombinant IL-2 was provided by Chiron Corp. Human recombinant IL-12, recombinant IL-4, and GM-CSF were from R\&D Systems. Monoclonal antibodies to HLA-DR, CD3, CD80, CD83, and CD86 were from CALTAG Laboratories; monoclonal antibodies to CD40, B7-H1, B7-DC, B7-RP1, and the blocking TL2.1 antibody against TLR2 were from eBioscience. Phytohemagglutinin $\mathrm{M}$ form (PHA) and staphylococcal protein G-Sepharose beads were purchased from Sigma-Aldrich. Mite allergen (D. pteronyssinus) was obtained from Lofarma Allergeni. Purified TT was from Chiron Corp. $\mathrm{PAM}_{2} \mathrm{Cys}-$ SKKKK $\times 3$ TFA (PAM2) and PAM $_{3}$ Cys-SKKKK $\times 3$ HCl (PAM3) synthetic lipopeptides were purchased from EMC microcollections GmbH. Purified recombinant CagA, VacA, and urease of $H$. pylori were kindly provided by J.L. Telford (Chiron Vaccines). WT H. pylori and HP-NAP-null H. pylori were prepared as described previously (38).

Preparation of neutrophils and monocytes. Human neutrophils were prepared from healthy donors as described previously using dextran sedimentation, centrifugation through Ficoll-Paque (Amersham Pharmacia Biotech), and hypotonic lysis of contaminating erythrocytes (39). Neutrophils were cultured in RPMI-10\% FCS (HyClone), in the presence of $1 \mu \mathrm{M}$ HP-NAP or PBS, as control. PBMCs from healthy donors were isolated by centrifugation on Ficoll-Paque solution and laid on Percoll 46\% $\mathrm{vol} / \mathrm{vol}$ solution (Amersham Biosciences) in RPMI 1640-10\% FCS and $4 \mathrm{mM}$ HEPES. Monocytes were harvested, resuspended in medium-2\% FCS, and separated from contaminating lymphocytes by adherence $\left(1\right.$ hour at $37^{\circ} \mathrm{C}$ ) to plastic. Adherent monocytes were extensively washed with medium to remove residual nonadherent cells. The percentages of CD $14^{+}$cells were greater than $98 \%$. Monocytes were then cultured in RPMI $1640-10 \%$ FCS in the presence of $1 \mu \mathrm{M}$ HP-NAP or PBS, as control.

Monocyte flow cytometry analysis. Monocytes $\left(2 \times 10^{6}\right.$ per well $)$ were seeded with HP-NAP $(1 \mu \mathrm{M})$ in 24-well plates in RPMI 1640-10\% FCS. At times 0, 5, and 7 days, cells were harvested and labeled with specific antibodies after saturation with human serum. All samples were analyzed by a BD FACSCalibur. Log MFI values were obtained by subtraction of the MFI of the isotype control from the MFI of the positively stained sample. To evaluate whether the differences between the peaks of cells were statistically significant with respect to control, the Kolmogorov-Smirnov test for analysis of histograms

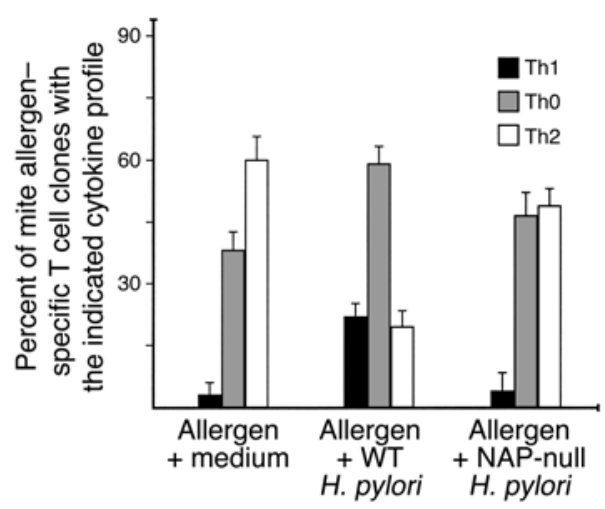

\section{Figure 6}

WT, but not HP-NAP-null mutant, $H$. pylori promotes the Th1 shift of allergen-specific T cells. Allergen-induced T cell lines were generated in the presence of medium alone, WT H. pylori, or HP-NAP-null $H$. pylori mutant $\left(5 \times 10^{5} \mathrm{CFUs} / \mathrm{ml}\right)$. T cell blasts of each line were then cloned, and allergen-specific $\mathrm{T}$ cell clones were stimulated for 48 hours with medium or allergen in the presence of irradiated autologous APCs. Culture supernatants were then collected and assayed for their IFN- $\gamma$ and IL-4 content. Results represent mean percentage proportions $( \pm S D)$ of clones with the indicated cytokine profile, obtained in $\mathrm{T}$ cell lines from 3 donors. 


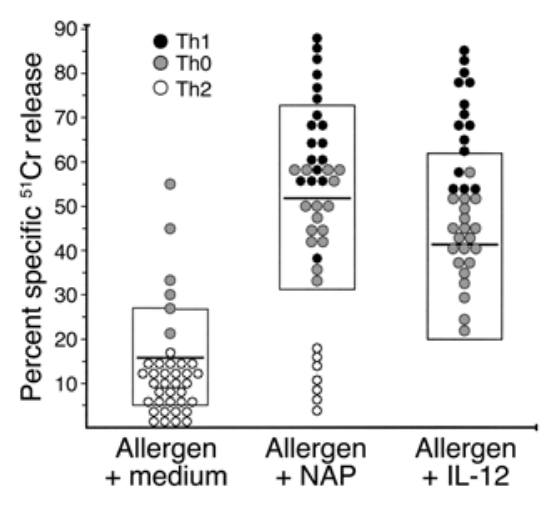

Figure 7

Cytotoxic activity of Th clones derived from allergen-induced $\mathrm{T}$ cell lines conditioned with medium alone, HP-NAP, or IL-12. Results represent the percentage specific ${ }^{51} \mathrm{Cr}$ release induced by single clones in PHA-treated murine ${ }^{51} \mathrm{Cr}$-labeled P815 mastocytoma cells at an effector-to-target ratio of $5: 1$. Horizontal bars and boxes indicate mean values $\pm S D$, respectively.

was used, according to the CellQuest software guide (BD). Flow cytometry data were expressed as means \pm SEM. Values were compared by ANOVA test, with $P$ values less than 0.05 considered significant.

Real-time PCR analysis. Total RNA was isolated from $2 \times 10^{6}$ monocytes or neutrophils using RNA Bee solution (Duotech) according to the manufacturer's instructions. RNA was reverse-transcribed and amplified with the following primers: 5'-AGCAACAGGGTGGTGGAC-3' and 5'-GTGTGGTGGGGGACTGAG-3' for GAPDH; 5'-ACAAAGGAGGCGAGGTTCTAA-3' and 5'-CCCTTGGGGGTCAGAAGAG-3' for IL-12p40; 5'-ATGGCCCTGTGCCTTAGTAGT-3' and 5'-CGGTTCTTCAAGGGAGGATTTT-3' for IL-12p35; 5'-TCCACCAGGGTCTGATTTTT-3' and 5'-TTGAAGCGGAGAAGGAGACG-3' for IL-23p19; and 5'-ATGAGCACTGAAAGCATGATCC-3' and $5^{\prime}$-GAGGGCTGATTAGAGAGAGGTC-3' for TNF- $\alpha$. After the amplification, data analysis was performed using the second derivative method algorithm. For each sample, the amount of cytokine mRNA (TNF- $\alpha$, IL-12p40, IL-12p35, IL-23p19) was expressed as $n$-fold of the normalized amount of mRNA from untreated cells $(1 \mathrm{AU}=\mathrm{mRNA}$ cytokine concentration $[\mathrm{fmol} / \mu \mathrm{l}] / \mathrm{mRNA}$ GAPDH $[\mathrm{fmol} / \mu \mathrm{l}])$.

Detection of IL-12p70 protein, TNF- $\alpha, I L-6$, and IL-8 in culture supernatants. Culture supernatants of monocytes, neutrophils, or DCs (23) harvested for mRNA quantification were collected at the same time points, and the amount of IL-12p70 protein was quantified by a commercial ELISA
(BioSource International). In some experiments, culture supernatants were also assayed for their TNF- $\alpha$, IL- 6 , and IL- 8 content by ELISA (BioSource International).

Screening assay of HP-NAP binding to TLRs (NF-KB reporter assay). HEK 293 cells were used for analysis of TLR-dependent activation, and NF-кBdependent reporter gene activation was used as readout $(25,26)$. Briefly, the analysis of HP-NAP TLR activation was performed on engineered HEK 293 cell lines constitutively expressing 1 single TLR (TLR2, TLR3, TLR4, TLR5, TLR7, TLR8, TLR9) as well as pNiFty (an ELAM1 reporter gene driven by NF-KB) purchased from InvivoGen. Each HEK 293-TLR cell line was induced with HP-NAP, and a known specific ligand as positive control. A recombinant HEK 293 cell line for the reporter gene only was used as a negative control. The negative control value represented the background signal. HP-NAP was tested in a range between $1 \mu \mathrm{M}$ and $0.1 \mathrm{nM}$. The positive control ligands tested were the following: PAM2 $(10 \mathrm{ng} / \mathrm{ml})$ from EMC microcollections GmbH for the HEK 293-human TLR2 (HEK 293-hTLR2) cell line; Poly(I:C) $(100 \mathrm{ng} / \mathrm{ml})$ from Amersham Biosciences for the HEK 293-hTLR3 cell line; LPS K12 $(100 \mathrm{ng} / \mathrm{ml})$ from InvivoGen for the HEK 293-hTLR4 cell line; flagellin $(1 \mu \mathrm{g} / \mathrm{ml})$ for the HEK 293-hTLR5 cell line; R848 $(10 \mu \mathrm{g} / \mathrm{ml})$ from GLSynthesis Inc. for both the HEK 293-hTLR7 and the HEK 293-hTLR8 cell line; and ODN 2006 from Amersham Biosciences $(10 \mu \mathrm{g} / \mathrm{ml})$ for the HEK 293-hTLR9 cell line. The various NF- $\mathrm{KB}$ activation assays were quantified as OD values after 24 hours of stimulation.

Generation of TT-specific T cell lines and ELISPOT assay. To evaluate IFN- $\gamma$ and IL-4 production by TT-specific T cells, commercial ELISPOT assays (Autoimmune Diagnostika $\mathrm{GmbH}$ ) were used, as described previously (40). Briefly, PBMCs from 5 TT-reactive donors were seeded $\left(1.5 \times 10^{6} \mathrm{per}\right.$ well) in 24-well flat-bottomed plates in $2 \mathrm{ml}$ RPMI 1640 medium supplemented with $5 \%$ human serum (complete medium) and were stimulated with TT $(0.5 \mu \mathrm{g} / \mathrm{ml})$ for 5 days. For each donor, 2 parallel TT-induced T cell lines were started: the first was added with medium alone, and the second with an optimal dose of HP-NAP $(0.3 \mu \mathrm{M})$. All lines were supplemented with IL-2 $(20 \mathrm{U} / \mathrm{ml})$ on day 6 and thereafter at 3 -day intervals. On day 12 , $\mathrm{T}$ cell blasts $\left(10^{5}\right.$ cells $)$ of each TT-induced line were stimulated with TT $(0.5 \mu \mathrm{g} / \mathrm{ml})$ in the presence of irradiated autologous APCs $\left(5 \times 10^{4}\right.$ cells $)$ and seeded in triplicate in 96-well plates coated with anti-IFN- $\gamma$ or antiIL-4 antibody. Cells stimulated with medium alone served as negative controls. IFN- $\gamma$ and IL-4 ELISPOT microplates were then incubated at $37^{\circ} \mathrm{C}$ in $5 \% \mathrm{CO}_{2}$ for 24 hours and 48 hours, respectively. At the end of the culture period, plates were washed and incubated for 3 hours with the appropriate biotinylated anti-IFN- $\gamma$ or anti-IL-4 mAb. Streptavidin-HRP complex was then added for 2 hours, followed by the substrate solution. SFCs were counted using an automated ELISPOT reader (Autoimmune Diagnostika $\mathrm{GmbH})$. The same procedures were used to prepare allergen-

\section{Table 5}

Cytokine profile and cytolytic activity of HP-NAP-specific CD4+ T cell clones derived from the gastric mucosa of $H$. pylori-infected patients

\section{Patients}

$\begin{array}{lc} & \text { T cell clones obtained (\%) } \\ 1 & 5 / 36(14) \\ 2 & 7 / 38(18) \\ 3 & 4 / 21(19) \\ 4 & 5 / 22(23) \\ 5 & 6 / 27(22) \\ \text { All patients } & 27 / 144(19)\end{array}$

$\begin{array}{cc}\begin{array}{c}\text { No. HP-NAP-specific CD4+ } \\ \text { T cell clones/CD4+ }\end{array} & \begin{array}{c}\text { No. HP-NAP-specific } \\ \text { clones with Th1 } \\ \text { cytokine profile }\end{array} \\ \begin{array}{c}\text { T cell clones obtained (\%) } \\ 5 / 36(14)\end{array} & 5 / 5 \\ 7 / 38(18) & 7 / 7 \\ 4 / 21(19) & 4 / 4 \\ 5 / 22(23) & 5 / 5 \\ 6 / 27(22) & 6 / 6 \\ 27 / 144(19) & 27 / 27\end{array}$

No. HP-NAP-specific
clones with
cytotoxic activity
$5 / 5$
$7 / 7$
$4 / 4$
$5 / 5$
$6 / 6$
$27 / 27$

In the series of CD4+ $\mathrm{T}$ cell clones obtained, clones specific for $\mathrm{H}$. pylori antigens other than HP-NAP (CagA, VacA, and urease) were 30 out of 144 (21\%). Among these 30 clones, 25 (83\%) showed a Th1 cytokine profile, whereas 5 were Th0. All clones produced levels of TNF- $\alpha$ comparable to those produced by HP-NAP-specific clones, and 27 of $30(90 \%)$ expressed cytotoxic activity. 
specific $T$ cell lines, to condition them with HP-NAP or other agents, and to stimulate with the specific allergen the expression of IFN- $\gamma$ or anti-IL-4 to be assessed by ELISPOT.

Generation of allergen-induced T cell lines and clones. PBMCs were obtained from 9 atopic donors ( 5 males and 4 females, median age 32 years, range 19-51) sensitive to mite allergen and suffering from mild asthma under treatment with inhaled steroids and $\beta_{2}$-agonists. All had increased serum IgE levels (>100 kU/l), positive D. pteronyssinus-specific IgE test, and positive skin prick test to mite allergen extract (Lofarma Allergeni). PBMCs were seeded $\left(1.5 \times 10^{6}\right.$ per well $)$ in 24-well flat-bottomed plates in $2 \mathrm{ml}$ complete medium and were stimulated with mite allergen $(1 \mu \mathrm{g} / \mathrm{ml})$ for 5 days. For each donor, 3 parallel allergen-induced $T$ cell lines were started: the first was added with medium alone, the second with HP-NAP $(0.3 \mu \mathrm{M})$, and the third with IL-12 $(100 \mathrm{pg} / \mathrm{ml})$. All lines were supplemented with IL-2 $(20 \mathrm{U} / \mathrm{ml})$ on day 6 and thereafter at 3-day intervals. The same protocol was applied to PBMCs from other allergic donors. For each donor, 3 parallel allergen-induced $\mathrm{T}$ cell lines were started: the first was induced with medium alone, the second with WT H. pylori $\left(5 \times 10^{5} \mathrm{CFUs} / \mathrm{ml}\right)$, and the third with HP-NAP-null $H$. pylori mutant $\left(5 \times 10^{5} \mathrm{CFUs} / \mathrm{ml}\right)$. On day 12 , $\mathrm{T}$ cell blasts were recovered, counted, and seeded under limiting-dilution conditions ( 0.3 cells per well) in roundbottomed microwell plates containing irradiated (60 Gy) PBMCs $\left(10^{5}\right.$ per well, as feeder cells) and PHA ( $1 \% \mathrm{vol} / \mathrm{vol})$ in a final volume of $0.2 \mathrm{ml}$ complete medium supplemented with IL-2 $(20 \mathrm{U} / \mathrm{ml})$, as reported previously (41). Growing microcultures were then supplemented at weekly intervals with IL-2 $(20 \mathrm{U} / \mathrm{ml})$ and $10^{5}$ irradiated feeder cells per well. The phenotype of $\mathrm{T}$ cell clones was examined by flow cytometry, and their mite allergen specificity was assessed by measurement of $\left[{ }^{3} \mathrm{H}\right] \mathrm{TdR}$ (Amersham Pharmacia Biotech) uptake after 60 hours of stimulation with mite allergen $(1 \mu \mathrm{g} / \mathrm{ml})$ under MHC-restricted conditions, as reported previously (27). When stimulation index (ratio between the mean cpm obtained in cultures stimulated with APCs plus allergen and the mean cpm obtained in cultures with APCs alone) was greater than 5 , responses were considered to be positive. Evidence for clonality of $\mathrm{T}$ cell clones was provided by the cytofluorimetric patterns of single TCR-V $\beta$ expression.

Generation of gastric T cell clones. Upon approval of the local Ethical Committee (Department of Internal Medicine, University of Florence), 5 patients ( 4 males and 1 female, median age 47 years, range $39-62$ ) with dyspeptic complaints gave their informed consent and were enrolled in the study. None of the patients had taken antibiotics or gastric proton pump inhibitors within 2 months before the study. Biopsy specimens were obtained during endoscopy from the gastric antrum for (a) histology and $H$. pylori detection, (b) rapid urease test, and (c) culture of infiltrating lymphocytes. Diagnosis of $H$. pylori infection was based on positive urease test, histologic detection of $\mathrm{H}$. pylori, and positive ${ }^{13} \mathrm{C}$-urea breath test. All patients were infected with $\mathrm{CagA}^{+} \mathrm{VacA}^{+} \mathrm{HP}_{-} \mathrm{NAP}^{+} \mathrm{H}$. pylori strains and showed severe active antral gastritis associated with duodenal ulcer. Biopsy specimens of gastric mucosa were cultured for 7 days in complete medium supplemented with IL-2 $(50 \mathrm{U} / \mathrm{ml})$ to preferentially expand in vivo-activated $\mathrm{T}$ cells. Specimens were then disrupted, and single $\mathrm{T}$ cell blasts were cloned by limiting dilution (6). T cell clones were then screened for responsiveness to medium, HP-NAP $(0.3 \mu \mathrm{M})$, CagA, VacA, and urease $(5 \mu \mathrm{g} / \mathrm{ml})$, by measurement of $\left[{ }^{3} \mathrm{H}\right] \mathrm{TdR}$ uptake after 60 hours.

1. Marshall, B.J., and Warren, J.R. 1984. Unidentified curved bacilli on gastric epithelium in active chronic gastritis. Lancet. 1:1311-1315.

2. Blaser, M.J., and Atherton, J.C. 2004. Helicobacter pylori persistence: biology and disease. J. Clin. Invest. 113:321-323. doi:10.1172/JCI200420925.

3. Goodwin, C.S. 1997. Helicobacter pylori gastritis, peptic ulcer and gastric cancer: clinical and molec-
Characterization of the cytokine profile of $T$ cell clones. To induce cytokine production by $\mathrm{T}$ cell clones in response to mite allergen, $\mathrm{T}$ cell blasts of each allergen-specific T cell clone $\left(5 \times 10^{5}\right)$ were cocultured in triplicate for 48 hours in $0.5 \mathrm{ml}$ medium with $5 \times 10^{5}$ irradiated autologous APCs in the presence of medium or mite allergen $(1 \mu \mathrm{g} / \mathrm{ml})$ (27). After 48 hours, culture supernatants were collected, filtered, and stored in aliquots at $-70^{\circ} \mathrm{C}$ until used. To induce cytokine production by gastric $\mathrm{T}$ cell clones, $\mathrm{T}$ cell blasts of each clone $\left(5 \times 10^{5}\right)$ were cocultured as indicated above in the presence of medium or HP-NAP $(0.3 \mu \mathrm{M})$, CagA, VacA, or urease $(5 \mu \mathrm{g} / \mathrm{ml})$, according to their specificity. Culture supernatants were assayed for IFN- $\gamma$, IL-4, and TNF- $\alpha$ content by commercial assays (BioSource International). Supernatants showing IFN- $\gamma$, IL-4, and TNF- $\alpha$ levels 5 SD over the mean levels in control supernatants derived from irradiated feeder cells alone were regarded as positive. $\mathrm{CD} 4^{+} \mathrm{T}$ cell clones able to produce IFN- $\gamma$, but not IL-4, were categorized as Th1; clones able to produce IL-4, but not IFN- $\gamma$, were categorized as Th 2 , and clones producing both IFN- $\gamma$ and IL-4 were categorized as Th0.

Assay for cytolytic activity. Cytolytic activity of clones was assessed as reported previously (6). Briefly, T cell blasts were washed 3 times, resuspended, and counted. All clones were tested for cytolytic activity against murine ${ }^{51} \mathrm{Cr}$-labeled P815 mastocytoma cells in the presence of PHA (1\% $\mathrm{vol} / \mathrm{vol}$ ) with an effector-to-target ratio of 5:1 and 1:1. After centrifugation to favor cell-to-cell contact followed by culture for 4 hours at $37^{\circ} \mathrm{C}, 0.1 \mathrm{ml}$ supernatant was removed for measurement of ${ }^{51} \mathrm{Cr}$ release. Maximum release (MR) was obtained by treatment of target cells with $0.1 \mathrm{ml} 1 \mathrm{M} \mathrm{HCl}$. Spontaneous release (SR) was determined in control microcultures without effector cells. Specific lysis was calculated according to the formula: $\%$ specific lysis $=100 \times($ experimental release $-\mathrm{SR}) /(\mathrm{MR}-\mathrm{SR})$. Cultures in which ${ }^{51} \mathrm{Cr}$ release exceeded the mean SR by more than $5 \mathrm{SD}$ were considered positive for cytolytic activity.

\section{Acknowledgments}

This work was supported by Italian Association for Cancer Research Regional grant proposal 2005 Veneto and Italian Ministry of University and Research (MIUR) grant 2004064334-06 to M. de Bernard; MIUR grant 2004065891-08 and Istituto Superiore di Sanità grant 4AM/F10 to G. Del Prete; and Fondazione Cassa di Risparmio di Firenze and the University of Florence to M.M. D'Elios. We thank C. Montecucco for the critical reading of the manuscript.

Received for publication October 20, 2005, and accepted in revised form January 24, 2006.

Address correspondence to: Mario M. D'Elios, Department of Internal Medicine, University of Florence, Viale Morgagni 85, 50134 Florence, Italy. Phone: 39055-4296-445; Fax: 39055-4271-494; E-mail: delios@unifi.it. Or to: Marina de Bernard, Venetian Institute of Molecular Medicine, Via Orus 2, 35128 Padua, Italy. Phone: 39049-7923-223; Fax: 39049-7923-250; E-mail: marina. debernard@unipd.it.

Amedeo Amedei and Andrea Cappon contributed equally to this work. specific for Helicobacter pylori in the gastric antrum of patients with peptic ulcer disease. J. Immunol. 158:962-967.

7. Reyrat, J.M., et al. 1999. Towards deciphering the Helicobacter pylori cytotoxin. Mol. Microbiol. 34:197-204.

8. Montecucco, C., and de Bernard, M. 2003. Molecular and cellular mechanisms of action of the vacuolating cytotoxin (VacA) and neutrophil-activating 
protein (HP-NAP) virulence factors of Helicobacter pylori. Microbes Infect. 5:715-721.

9. Molinari, M., et al. 1998. Selective inhibition of Ii-dependent antigen presentation by Helicobacter pylori toxin VacA. J. Exp. Med. 187:135-140.

10. Boncristiano, M., et al. 2003. The Helicobacter pylori vacuolating toxin inhibits $\mathrm{T}$ cell activation by two independent mechanisms. J. Exp. Med. 198:1887-1897.

11. Evans, D.J., Jr., et al. 1995. Characterization of a Helicobacter pylori neutrophil-activating protein. Infect. Immun. 63:2213-2220.

12. Montemurro, P., et al. 2001. Helicobacter pylori neutrophil-activating protein stimulates tissue factor and plasminogen activator inhibitor-2 production by human blood mononuclear cells. J. Infect. Dis. 183:1055-1062.

13. Telford, J.L., et al. 1994. Gene structure of the Helicobacter pylori cytotoxin and evidence of its key role in gastric disease. J. Exp. Med. 179:1653-1658.

14. Trinchieri, G. 2003. Interleukin-12 and the regulation of innate resistance and adaptative immunity. Nat. Rev. Immunol. 3:133-146.

15. Snijders, A., et al. 1996. Regulation of bioactive IL-12 production in lipopolysaccharide-stimulated human monocytes is determined by the expression of the p35 subunit. J. Immunol. 156:1207-1212.

16. Oppmann, B., et al. 2000. Novel p19 engages IL-12p40 to form a cytokine, IL-23, with biological activities similar as well as distinct from IL-12. Immunity. 13:715-725.

17. Takeda, K., Kaisho, T., and Akira, S. 2003. Toll-like receptors. Annu. Rev. Immunol. 21:335-376.

18. Medzhitov, R. 2001. Toll-like receptors and innate immunity. Nat. Rev. Immunol. 1:135-145.

19. Alexopoulou, L., Holt, A.C., Medzhitov, R., and Flavell, R.A. 2001. Recognition of double-stranded RNA and activation of NF-kB by Toll-like receptor 3 . Nature. 413:732-738.

20. Medzhitov, R., Preston-Hurlburt, P., and Janeway, C.A., Jr. 1997. A human homologue of the Drosophila Toll protein signals activation of adaptive immunity. Nature. 388:394-397.
21. Poltorak, A., et al. 1998. Defective LPS signaling in $\mathrm{C} 3 \mathrm{H} / \mathrm{HeJ}$ and $\mathrm{C} 57 \mathrm{BL} / 10 \mathrm{ScCr}$ mice: mutations in Tlr4 gene. Science. 282:2085-2088.

22. Hemmi, H., et al. 2000. A Toll-like receptor recognizes bacterial DNA. Nature. 408:740-745.

23. Napolitani, G., Rinaldi, A., Bertoni, F., Sallusto, F., and Lanzavecchia, A. 2005. Selected Toll-like receptor agonist combinations synergistically trigger a $\mathrm{T}$ helper type 1-polarizing program in dendritic cells. Nat. Immunol. 6:769-776.

24. Schindler,U., andBaichwal,V.R. 1994. ThreeNF-kappaB binding sites in the human E-selectin gene required for maximal tumor necrosis factor alpha-induced expression. Mol. Cell. Biol. 14:5820-5831.

25. Jensen, L.E., and Whitehead, A.S. 2003. ELAM-1/ E-selectin promoter contains an inducible AP-1/ CREB site and is not NF-KB-specific. Biotechniques. 35:54-58.

26. Akira, S., and Taheda, K. 2004. Toll-like receptor signalling. Nat. Rev. Immunol. 4:499-511.

27. Del Prete, G., et al. 1993. Allergen exposure induces the activation of allergen-specific Th2 cells in the airway mucosa of patients with allergic respiratory disorders. Eur. J. Immunol. 23:1445-1449.

28. Del Prete, G., De Carli, M., Ricci, M., and Romagnani, S. 1991. Helper activity for immunoglobulin synthesis of T helper type 1 (Th1) and Th2 human T cell clones: the help of Th 1 clones is limited by their cytolytic capacity. J. Exp. Med. 174:809-813.

29. Grant, R.A., Filman, D.J., Finkel, S.E., Kolter, R., and Hogle, J.M. 1998. The crystal structure of Dps, a ferritin homolog that binds and protects DNA. Nat. Struct. Biol. 5:294-303.

30. Tonello, F., et al. 1999. The Helicobacter pylori neutrophil-activating protein is an iron-binding protein with dodecameric structure. Mol. Microbiol. 34:238-246.

31. Tomb, J.-F., et al. 1997. The complete genome sequence of the gastric pathogen Helicobacter pylori. Nature. 388:539-547.

32. Zanotti, G., et al. 2002. Structure of the neutrophilactivating protein from Helicobacter pylori. J. Mol. Biol. 323:125-130.
33. Bancherau, J., and Steinman, R.M. 1998. Dendritic cells and the control of immunity. Nature. 392:245-252.

34. Reis e Sousa, C., Sher, A., and Kaye, P. 1999. The role of dendritic cells in the induction and regulation of immunity to microbial infection. Curr. Opin. Immunol. 11:392-399.

35. Dixon, G.L., et al. 2001. Dendritic cell activation and cytokine production induced by group B Neisseria meningitidis: interleukin-12 production depends on lipopolysaccharide expression in intact bacteria. Infect. Immun. 69:4351-4357.

36. Kranzer, K., et al. 2004. Induction of maturation and cytokine release of human dendritic cells by Helicobacter pylori. Infect. Immun. 72:4416-4423.

37. Dundon, W.G., Polenghi, A., Del Guidice, G., Rappuoli, R., and Montecucco, C. 2001. Neutrophilactivating protein (HP-NAP) versus ferritin (Pfr): comparison of synthesis in Helicobacter pylori. FEMS Microbiol. Lett. 199:143-149.

38. Montemurro, P., et al. 2001. Helicobacter pylori neutrophil-activating protein stimulates tissue factor and plasminogen activator inhibitor-2 production by human blood mononuclear cells. J. Infect. Dis. 183:1055-1062.

39. Rossi, F., Della Bianca, V., Grzeskowiak, M., and Bazzoni, F. 1989. Studies on molecular regulation of phagocytosis in neutrophils. Con A-mediated ingestion and associated respiratory burst independent of phosphoinositide turnover, rise in $\left[\mathrm{Ca}^{2+}\right]$, and arachidonic acid release. J. Immunol. 142:1652-1660.

40. Reece, W.H.H., et al. 2004. A CD4 ${ }^{+}$T-cell immune response to a conserved epitope in the circumsporozoite protein correlates with protection from natural Plasmodium falciparum infection and disease. Nat. Med. 10:406-410.

41. Del Prete, G., et al. 1991. Purified protein derivative of Mycobacterium tuberculosis and excretory-secretory antigen(s) of Toxocara canis expand in vitro human $\mathrm{T}$ cells with stable and opposite (type $1 \mathrm{~T}$ helper or type $2 \mathrm{~T}$ helper) profile of cytokine production. J. Clin. Invest. 88:346-350. 